\title{
Study of the frequency of female genital tract infection using cartridge based nucleic acid amplification test
}

\author{
Drishti Chaudhary ${ }^{1 *}$, Mamta Tyagi ${ }^{1}$, Smriti Gupta $^{1}$, Lalita Yadav ${ }^{1}$, Anita Pandey ${ }^{2}$
}

\begin{abstract}
${ }^{1}$ Department of Obstetrics and Gynecology, ${ }^{2}$ Department of Microbiology, Swami Vivekanand Subharti University, Meerut, Uttar Pradesh, India
\end{abstract}

Received: 18 December 2021

Accepted: 10 January 2022

\section{*Correspondence:}

Dr. Drishti Chaudhary,

E-mail: drishti7011@gmail.com

Copyright: (C) the author(s), publisher and licensee Medip Academy. This is an open-access article distributed under the terms of the Creative Commons Attribution Non-Commercial License, which permits unrestricted non-commercial use, distribution, and reproduction in any medium, provided the original work is properly cited.

\begin{abstract}
Background: The aim of the study was to study the frequency of female genital tract infection using cartridge based nucleic acid amplification test (CBNAAT), to study the sensitivity, specificity, positive predictive value, negative predictive value and diagnostic accuracy of CBNAAT.

Methods: This prospective observational study was conducted among 100 patients as per inclusion criteria with genital tract infection in Swami Vivekanand Subharti University, Meerut over a period of two years. Investigations including $\mathrm{ZN}$ staining for acid fast bacillus (AFB), endometrial sampling for histopathology, CBNAAT and BACTEC culture were sent.

Results: In a study of 100 patients' histopathological examination detected tuberculosis in 2\% patients while CBNAAT detected tuberculosis in 5\% patients. Tubercle bacilli was found in 3\% women on AFB stain while in only $1 \%$-woman genital tuberculosis was diagnosed by BACTEC culture.

Conclusions: Female genital tuberculosis is detected most frequently when a woman presents with unexplained infertility. Newer technologies allow genital tuberculosis to be identified at an earlier stage and enable us to provide treatment. CBNAAT being a sensitive test picked up more cases than histopathology, culture, AFB stain. Hence CBNAAT should be widely used for early detection of female genital tuberculosis.
\end{abstract}

Keywords: CBNAAT, Tuberculosis, Tubercle bacilli

\section{INTRODUCTION}

Tuberculosis (TB) is one of the oldest diseases as old as human civilization. ${ }^{1}$ It is a chronic infectious disease and the morbidity associated with this condition has major health implications. ${ }^{2}$ Throughout the world tuberculosis affects about 9.4 million people annually with about two million deaths. ${ }^{3,4}$ Apart from commonest and the most infectious pulmonary TB, extra pulmonary TB (EPTB) is being increasingly encountered throughout the world. ${ }^{5}$ Female genital TB (FGTB) is an important cause of significant morbidity, short-and long-term sequelae especially infertility. ${ }^{5-8}$ Genital TB is mostly secondary to pulmonary TB or extrapulmonary foci. The genital organs affected by Mycobacterium tuberculosis (in descending order of frequency) are as follows: fallopian tubes (95-
$100 \%)$, uterine endometrium (50-60\%), ovaries (20-30\%), cervix $(5-15 \%)$, uterine myometrium $(2.5 \%)$ and vagina/vulva (1\%). ${ }^{9}$ CBNAAT is a semi quantitative real time PCR for both mycobacterium tuberculosis (MTB) as well as detecting genetic mutations associated with the resistance to the drug rifampicin. CBNAAT by virtue of using 3 primers and 5 probes is a completely automated highly specific test with metanalysis of literature reporting sensitivity at $90.4 \%$ and specificity of $98.4 \%$ in pulmonary TB identification. ${ }^{10}$

\section{METHODS}

This prospective observational study was conducted among all OPD and IPD suspected patients of genital tract 
infection of Subharti medical college, Meerut, over a period of two years.

An ethical clearance was approved by the institutional review board for ethical clearance of the institution (Subharti medical college).

Sample size was 100 and calculated by $n=z^{2} \mathrm{pq} / \mathrm{d}^{2}$

On calculation " $n$ " was equal to 125.79 , which was rounded off to 126 .

\section{Inclusion criteria}

All OPD and IPD patients were included in the study.

\section{Exclusion criteria}

Pregnancy and pregnancy related problems, patient on ATT, infertile women with known male factor infertility and immunocompromised patients were excluded from the study.

A detailed history regarding current complaints of the patient, age, menstrual and gynecological history, family history and past history of tuberculosis and history of any treatment was undertaken. A systemic and gynecological examination was done. Investigations which include $\mathrm{ZN}$ staining for AFB, endometrial sampling for histopathology, CBNAAT and BACTEC culture were sent after taking written and informed consent for participation in the study. Endometrial samples were obtained by gentle aspiration or curettage using Karmann's cannula under paracervical block. One part of biopsy was subjected to histopathological examination (in formalin) and second part was sent to lab for CBNAAT, culture media and AFB stain (in normal saline).

\section{Statistical analysis}

Data was analyzed using SPSS software version 24. Sensitivity, specificity, positive predictive value and negative predictive value was calculated.

\section{RESULTS}

Out of 100 women maximum were from the age group of 21-30years (Table 1). histopathological examination (HPE) detected tuberculosis in $2(2 \%)$ patients while CBNAAT detected tuberculosis in $5(5 \%)$ patients. Tubercle bacilli was found in $3(3 \%)$ women on AFB stain while in only $1(1 \%)$ woman genital tuberculosis was diagnosed by BACTEC culture. Sensitivity, specificity, positive predictive value, negative predictive value and diagnostic accuracy of CBNAAT considering HPE as gold standard was $100 \%, 97.03 \%, 99.84 \%, 100 \%$ and $99.85 \%$ of the subjects respectively (Table 2). Sensitivity, specificity, positive predictive value, negative predictive value and diagnostic accuracy of CBNAAT considering AFB stain as gold standard was 100\%, 97.89\%, 99.89\%,
$100 \%$ and $99.89 \%$ of the subjects respectively (Table 3 ). Sensitivity, specificity, positive predictive value, negative predictive value and diagnostic accuracy of CBNAAT considering culture as gold standard was $100 \%, 95.96 \%$, $99.79 \%, 100 \%$ and $98.80 \%$ of the subjects respectively (Table 4).

Table 1: Distribution of women according to age.

\begin{tabular}{|lll|}
\hline Age group (years) & $\mathbf{N}$ & Percentage (\%) \\
\hline $\mathbf{2 1 - 3 0}$ & 61 & 61 \\
\hline $\mathbf{3 1 - 4 0}$ & 32 & 32 \\
\hline $\mathbf{> 4 0}$ & 7 & 7 \\
\hline Total & 100 & 100 \\
\hline
\end{tabular}

Table 2: Diagnostic efficacy of CBNAAT considering HPE as gold standard.

\begin{tabular}{|lllll|}
\multirow{2}{*}{ Variables } & & \multicolumn{2}{c}{ CBNAAT } & Total \\
\hline \multirow{2}{*}{ HPE } & +ve & -ve & \\
\cline { 2 - 5 } & +ve & 2 & 0 & 2 \\
\hline Total & -ve & 3 & 95 & 98 \\
\hline
\end{tabular}

Table 3: Diagnostic efficacy of CBNAAT considering AFB stain as gold standard.

\begin{tabular}{|lllll|}
\hline \multirow{2}{*}{ Variables } & & \multicolumn{2}{c}{ CBNAAT } & Total \\
\hline $\begin{array}{l}\text { AFB } \\
\text { stain }\end{array}$ & +ve & 3 & -ve & \\
\hline Total & -ve & 2 & 0 & 3 \\
\hline
\end{tabular}

Table 4: Diagnostic efficacy of CBNAAT considering BACTEC culture as gold standard.

\begin{tabular}{|c|c|c|c|c|}
\hline \multirow{2}{*}{ Variables } & & \multicolumn{2}{|c|}{ CBNAAT } & \multirow{2}{*}{ Total } \\
\hline & & +ve & -ve & \\
\hline \multirow{2}{*}{ Culture } & +ve & 1 & 0 & 1 \\
\hline & -ve & 4 & 95 & 99 \\
\hline Total & & 5 & 95 & 100 \\
\hline
\end{tabular}

\section{DISCUSSION}

Out of 100 subjects, maximum subjects were from the age group of 21-30 years. Garg et al in their study too revealed that maximum patients were from age group 26-30 years $(43.20 \%) .{ }^{11}$ In our study $8 \%$ women gave history of some family member suffering from tuberculosis. In a study by Arpitha et al $11.1 \%$ patients had a previous history of extra genital TB. ${ }^{13}$ In our study $10 \%$ women had complaint of heavy menstrual bleeding while $11 \%$ had reduced menstrual flow, 25\% women had delayed cycles and $7 \%$ women complained of amenorrhoea, whereas $13 \%$ women complained of dysmenorrhoea. Similar findings were reported in a study by Sharma where normal menstrual pattern was seen in $57.6 \%$ of patients and most common menstrual abnormality was hypomenorrhoea in $30.1 \%$ followed by oligomenorrhoea in $3.5 \% .^{12}$ In our study, 3 
women showed evidence of endometritis on HPE, $2 \%$ women among them had tuberculous endometritis while only $1 \%$ had nonspecific endometritis. Of the remaining 97 women, $38 \%$ had proliferative endometrium and $59 \%$ women had secretory endometrium. In 2018 a study was conducted by Garg et al on GeneXpert test and endometrial histological findings in infertile women. ${ }^{11}$ In this study secretory endometrium was found in $55.55 \%$ cases, proliferative endometrium (anovulatory) in $41.9 \%$ cases, non-specific endometritis in $1.23 \%$ case.However in our study due to COVID, we were able to recruit 100 subjects.

\section{CONCLUSION}

Female genital tuberculosis is detected most frequently when a woman presents with unexplained infertility. Newer technologies allow genital tuberculosis to be identified at an earlier stage and enable us to provide treatment. CBNAAT being a sensitive test picked up more cases than histopathology, culture, AFB stain. Hence CBNAAT should be widely used for early detection of female genital tuberculosis.

\section{ACKNOWLEDGMENTS}

Author would like to thanks to everyone who played a role in this research. Obstetrics and gynecology faculty for their patient advice and guidance throughout the research.

\section{Funding: No funding sources}

Conflict of interest: None declared

Ethical approval: The study was approved by the Institutional Ethics Committee

\section{REFERENCES}

1. Rao KN. History of tuberculosis. In: Text book of Tuberculosis-2nd Edition. Vikas Publishing house. 1981.

2. Sharma D, Depan A, Yadav K, Narayan S, Sharma A. Prevalence of female genital tract tuberculosis in suspected cases attending Gynecology OPD at tertiary centre by various diagnostic methods and comparative analysis. Int J Reprod Contracept Obstet Gynecol. 2019;8:2286-92.

3. Dye C, Watt CJ, Bleed DM. Evolution of tuberculosis control and prospects for reducing tuberculosis incidence, prevalence and deaths globally. JAMA. 2005;293:2790-3.

4. World Health Organization. Global tuberculosis control: a short update to the 2009 report. WHO/HTM/TB 2009, 426. Geneva: WHO. 2009. Available at: https://www.who.int/news-room/factsheets/detail/tuberculosis. Accessed on 1 July 2021.

5. Kumar S. Female genital tuberculosis. In: Sharma SK, Mohan A, editors. Tuberculosis 3rd ed. Delhi: Jaypee Brothers Medical Publisher Ltd. 2015;311-24.

6. Neonakis IK, Spandidos DA, Petinaki E. Female genital tuberculosis: a review. Scand J Infect Dis. 2011;43(8):564-72.

7. Sharma JB. Tuberculosis and obstetric and gynecological practice. In: Studd J, Tan SL, Chervenak FA, editors. Progress in obstetrics and gynecology, Philadelphia: Elsevier. 2008;18:395-427.

8. Das P, Ahuja A, Gupta SD. Incidence, etiopathogenesis and pathological aspects of genitourinary tuberculosis in India: A journey revisited. Indian J Urol. 2008;24:356-61.

9. Grace GA, Devaleenal DB, Natrajan M. Genital tuberculosis in females. Indian J Med Res. 2017;145(4):425-36.

10. Kai C, Lu W, Junji W, Kejun Z, Shuangrong J, Fake L et al. Rapid and effective diagnosis of tuberculosis and rifampicin resistance with Xpert MTB/RIF assay: A meta-analysis. J Infect. 2012;64:580-8.

11. Garg R, Agarwal N, Gupta M. GeneXpert test and endometrial histological findings in infertile women. Int J Reprod Contracept Obstet Gynecol. 2018;7:1480-3.

12. Sharma JB, Roy KK, Pushpraj M. Genital tuberculosis: an important cause of Asherman's syndrome in India. Arch Gynecol Obstet. 2008;277:37-41.

13. Arpitha VJ, Savitha C, Nagarathnamma R. Diagnosis of genital tuberculosis: correlation between polymerase chain reaction positivity and laparoscopic findings. Int J Reprod Contracept Obstet Gynecol. 2016;5:3425-32.

Cite this article as: Chaudhary D, Tyagi M, Gupta S Yadav L, Pandey A. Study of the frequency of female genital tract infection using cartridge based nucleic acid amplification test. Int J Reprod Contracept Obstet Gynecol 2022;11:357-9. 